\title{
Chronic proximal spinal muscular atrophy of childhood and adolescence: sex influence
}

\author{
IRENA HAUSMANOWA-PETRUSEWICZ*, JACEK ZAREMBA $\dagger$, \\ JANINA BORKOWSKA*, AND WALENTINA SZIRKOWIEC $\dagger$ \\ From *the Department of Neurology, Medical School, and †Department of Genetics, Psychoneurological \\ Institute, Warsaw, Poland.
}

SUMMARY Segregation analysis was performed on 354 cases of chronic proximal spinal muscular atrophy of childhood and adolescence (CPSMA) in the total series and in a number of subgroups formed according to the age at onset and sex.

The analysis provided evidence of sex influence in the series studied, particularly in a subgroup of the milder form of the disease with onset between the 37th month and 18th year of life. In the latter subgroup, females were affected much less frequently. This was particularly striking after age at onset of 8 years, and only exceptionally were females affected after the age of 13 years. These facts point to incomplete penetrance of the gene.

The problem of the predominance of males in spinal muscular atrophy (SMA) of childhood and adolescence has been infrequently discussed in publications. However, closer analysis of reported data shows that, although unnoticed, the sex dependent differences have been present in many series. ${ }^{1-3}$ Only a few authors have stressed the predominance of males or the milder course of the disease in females. ${ }^{4-6}$

No sex differences were present in the series composed mainly of acute cases of $\mathrm{SMA}^{7-10}$ or in the cases of predominantly early onset. ${ }^{11}$ However, some authors have noticed that the course of the infantile form of the disease is more severe in males. ${ }^{612-17}$ Furukawa et $a l^{6}$ were of the opinion that SMA, and in particular the Kugelberg-Welander form, was a sex influenced condition.

We have previously presented data showing the influence of sex in a chronic proximal form of spinal muscular atrophy of childhood and adolescence (CPSMA)*. ${ }^{17} 18$ The segregation ratio in our material ${ }^{18}$ appeared higher for males than for females and the distribution of age at onset of the disease was clearly different in each sex. In an attempt to explain this we postulated a tentative hypothesis of genetic modification..$^{18}$ Our analysis has shown

\footnotetext{
*Terms used for the same condition in other publications: (1) chronic form of childhood spinal muscular atrophy, (2) chronic forms of infantile and juvenile spinal muscular atrophy, (3) benign juvenile pseudodystrophic spinal muscular atrophy. This is a synonym of iuvenile muscular atrophy or the Kugelberg-Welander form of the disease.

Received for publication 20 October 1983.

Accepted for publication 21 February 1984.
}

that sex differences were particularly pronounced in the benign cases of CPSMA. ${ }^{19}$

The aim of the present study was a further analysis, partly based on results obtained by one of us, ${ }^{20}$ of the sex influence in CPSMA.

\section{Material and methods}

The present study is based on 354 cases originating from 264 sibships registered by the Department of Neurology, Medical School of Warsaw, in the years 1960 to 1982 . Grouping of the cases according to the classification of Hausmanowa-Petrusewicz et al $^{21}$ is shown in table 1. As can be seen in the table,

TABLE 1 Clinical forms of 354 cases of SMA based on modified classification of Hausmanowa-Petrusewicz et al. ${ }^{21}$

\begin{tabular}{lccc}
\hline SMA form & $M$ & $F$ & $M$ and $F$ \\
\hline IA & 25 & 21 & 46 \\
IB & 71 & 68 & 139 \\
II & 30 & 40 & 70 \\
III & 63 & 36 & 99 \\
Total & 189 & 165 & 354 \\
\hline
\end{tabular}

Form IA-acute, onset recorded at birth, never able to walk, survival up to 4 years.

Form IB-chronic, onset recorded at birth or in early months of life, never able to walk, survival up to 30 years.

Form II-age at onset first to fifth year, immobilised usually between tenth and fourteenth year, long survival.

Form III-age at onset from first year to adolescence, never complete immobilisation, long survival.

Relevant nomenclature:

Acute form of Werdnig-Hoffmann-corresponding to IA.

Intermediate form-corresponding to IB and II.

Mild form of Kugelberg-Welander-corresponding to III. 
there was a subgroup of 46 acute cases of SMA (form IA). In view of the small size of this subgroup we decided not to exclude it from the material, especially since other criteria of the acute form of SMA assume a lower age of survival and this subgroup would be even smaller.*

Segregation analysis was carried out on the age at onset and sex of the affected subjects. Segregation ratios for each sex separately were calculated in six age at onset subgroups (table 2) and in five cumulative age at onset subgroups (table 3). Division of the material into so many subgroups enabled us to detect the sex differences expressed in genetic ratios ( $p$ values) in different ranges of age at onset. The obvious limitation of such divisions was the fact that the size of some subgroups was not large enough for meaningful statistical analysis. Segregation ratios were simply calculated by dividing the total number of affected subjects by the total number of children after subtraction (from both numbers) of the total number of probands, an approach also used by other authors. ${ }^{1222}$ We also compared the $p$ values in different clinical types of CPSMA (table 4) according to the classification provided in table 1. Sibships which, owing to the different ages at onset of the affected sibs, would qualify for more than one subgroup were excluded.

Initially a significant difference between $p$ values for males and females was found in the subgroup with earliest onset. It was noticed, however, that in our series this was mainly the result of the relatively larger number of probands among affected females. Introduction of a correction, based upon the assumption that probabilities of ascertainment of affected males and females do not differ, abolished the apparent sex differences in $p$ values in this subgroup.

\section{Results}

The results are presented in tables 2,3 , and 4 . It is apparent that $p$ values are highest in the lowest age at onset subgroup 0 to 3 months (table 3 ). In one of the subgroups (10 to 36 months) the $p$ values are low. The sudden fall of the $p$ value in this age range (table 2) could suggest heterogeneity of the material. In the subgroup 37 months to 8 years the $p$ values again are close to the expected 0.25 level. The same is true of males in the age range 9 to 18 years. However, if both sexes are taken jointly, the $p$ value in this subgroup drops below the 0.1 level, because, after exclusion of the probands, there are no female cases with onset after the age of 8 years (table 2). As the results presented in table 4 show, form I of

*It would be halved if the criteria of Pearn et al10 were applied, according to which survival in the acute form of SMA never exceeds the third year of life.

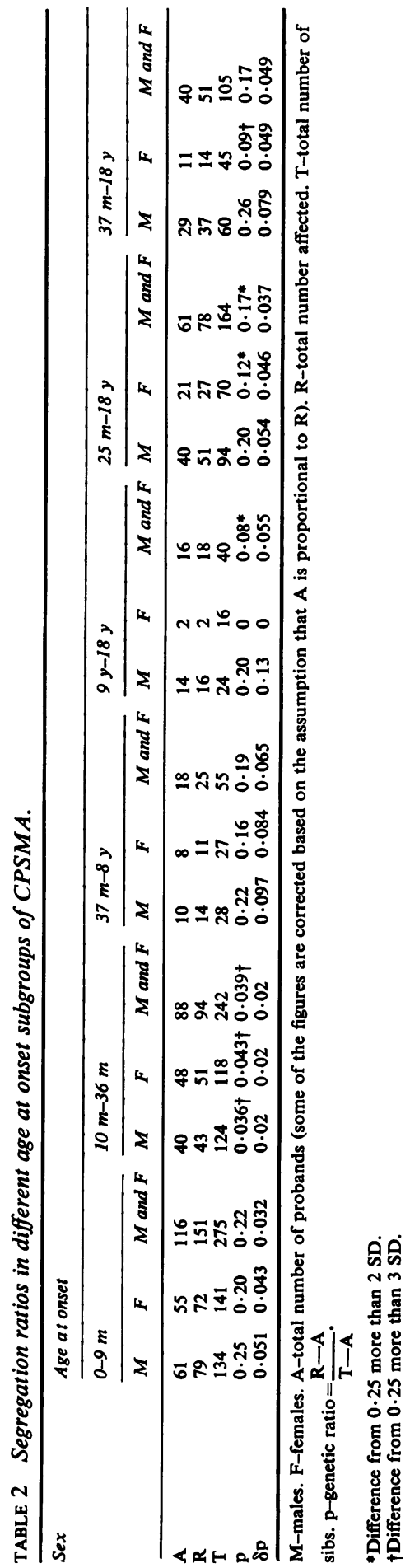


TABLE 3 Segregation ratios in some cumulated age at onset subgroups of CPSMA.

\begin{tabular}{|c|c|c|c|c|c|c|c|c|c|c|c|c|c|c|c|}
\hline \multirow[t]{3}{*}{ Sex } & \multicolumn{15}{|c|}{ Age at onset } \\
\hline & \multicolumn{3}{|l|}{$0-3 m$} & \multicolumn{3}{|c|}{$0-12 \mathrm{~m}$} & \multicolumn{3}{|c|}{$0-24 m$} & \multicolumn{3}{|c|}{$0-36 \mathrm{~m}$} & \multicolumn{3}{|l|}{$0-18 y$} \\
\hline & $\boldsymbol{M}$ & $F$ & $M$ and $F$ & $M$ & $F$ & $M$ and $F$ & $M$ & $\boldsymbol{F}$ & $M$ and $F$ & $\boldsymbol{M}$ & $\boldsymbol{F}$ & $M$ and $F$ & $M$ & $\boldsymbol{F}$ & $M$ and $F$ \\
\hline $\begin{array}{l}\mathbf{A} \\
\mathbf{R} \\
T \\
\mathrm{p} \\
8 \mathrm{p}\end{array}$ & $\begin{array}{l}53 \\
71 \\
117 \\
0.28 \\
0.056\end{array}$ & $\begin{array}{l}45 \\
61 \\
119 \\
0 \cdot 22 \\
0.048\end{array}$ & $\begin{array}{l}98 \\
132 \\
236 \\
0 \cdot 25 \\
0.034\end{array}$ & $\begin{array}{l}81 \\
104 \\
195 \\
0.20 \\
0.037\end{array}$ & $\begin{array}{l}77 \\
99 \\
202 \\
0 \cdot 18^{*} \\
0 \cdot 034\end{array}$ & $\begin{array}{l}158 \\
203 \\
397 \\
0.18^{*} \\
0.025\end{array}$ & $\begin{array}{l}106 \\
130 \\
261 \\
0.15 t \\
0.029\end{array}$ & $\begin{array}{l}103 \\
127 \\
268 \\
0 \cdot 15 \dagger \\
0 \cdot 028\end{array}$ & $\begin{array}{l}209 \\
257 \\
529 \\
0 \cdot 15 \dagger \\
0.020\end{array}$ & $\begin{array}{l}117 \\
143 \\
294 \\
0 \cdot 15 \dagger \\
0.027\end{array}$ & $\begin{array}{l}117 \\
144 \\
302 \\
0.15 \dagger \\
0.026\end{array}$ & $\begin{array}{l}234 \\
287 \\
596 \\
0.15 t \\
0.019\end{array}$ & $\begin{array}{l}153 \\
189 \\
377 \\
0.16 \dagger \\
0.024\end{array}$ & $\begin{array}{l}133 \\
165 \\
365 \\
0 \cdot 14 \dagger \\
0.023\end{array}$ & $\begin{array}{l}286 \\
354 \\
742 \\
0.15^{*} \\
0.017\end{array}$ \\
\hline
\end{tabular}

TABLE 4 Segregation ratios in different forms of CPSMA according to classification provided in table 1.

\begin{tabular}{|c|c|c|c|c|c|c|c|c|c|}
\hline \multirow[t]{3}{*}{$\operatorname{Sex}$} & \multicolumn{9}{|c|}{ Clinical forms } \\
\hline & \multicolumn{3}{|l|}{$I$} & \multicolumn{3}{|l|}{ II } & \multicolumn{3}{|l|}{ III } \\
\hline & $M$ & $F$ & $M$ and $F$ & $M$ & $F$ & $M$ and $F$ & $M$ & $F$ & $M$ and $F$ \\
\hline $\begin{array}{l}\mathbf{A} \\
\mathbf{R} \\
\mathbf{T} \\
\mathbf{p} \\
\delta \mathbf{p}\end{array}$ & $\begin{array}{l}79 \\
94 \\
161 \\
0 \cdot 26 \\
0.046\end{array}$ & $\begin{array}{l}64 \\
87 \\
163 \\
0 \cdot 23 \\
0.042\end{array}$ & $\begin{array}{l}134 \\
181 \\
324 \\
0.25 \\
0.03\end{array}$ & $\begin{array}{l}24 \\
27 \\
83 \\
0 \cdot 05 \dagger \\
0.03\end{array}$ & $\begin{array}{l}33 \\
37 \\
76 \\
0.09 \dagger \\
0.044\end{array}$ & $\begin{array}{l}57 \\
64 \\
159 \\
0.07 \dagger \\
0.03\end{array}$ & $\begin{array}{l}52 \\
61 \\
113 \\
0.15 \dagger \\
0.05\end{array}$ & $\begin{array}{l}29 \\
34 \\
108 \\
0.06 \dagger \\
0.03\end{array}$ & $\begin{array}{l}81 \\
95 \\
221 \\
0.1 \dagger \\
0.03\end{array}$ \\
\hline
\end{tabular}

the disease corresponds roughly to the age at onset 0 to 3 months in table 3 . A large proportion of the cases in form II appear to fit well to the age range of 10 to 36 months and in form III to the age range 37 months to 18 years.

\section{Discussion}

Most of the estimates of genetic ratios in these series may be considered as characteristic of autosomal recessive transmission of the gene, and in fact we did not observe any pedigrees which would provide evidence of other forms of inheritance, with the exception of one pedigree which suggested $X$ linked transmission. ${ }^{18}$ In such a large series, however, it could have occurred simply by chance.

The sex dependent differences in $\mathrm{p}$ values become obvious from the age at onset of $\mathbf{3 7}$ months upwards. They seem to start in the subgroup between 37 months and 8 years and between 9 and 18 years they are highly significant $(p<0.001)$. They are also significant in some other subgroups, namely 25 months to 18 years $(\mathrm{p}<0 \cdot 05), 37$ months to 18 years $(\mathrm{p}<0.01)$, and in form III of the disease $(\mathrm{p}<0.01)$. In the material taken as a whole (age range 0 to 18 years) the differences are not significant owing to the overwhelming majority of the earlier onset cases. Nevertheless it appears to us that our data provide good evidence that CPSMA is a sex influenced condition, based on the lower number of females in the later onset subgroups and, therefore, decreased $p$ values for females. These facts are in keeping with the previous studies of male-female sib pairs, which have shown that the disease has a milder course in females. ${ }^{13} 17$

In the age range 0 to 9 months the penetrance of the gene is complete and between 10 and 36 months there is a sudden lowering in $p$ values (table 2). The reduction in female cases in the later age at onset ranges starting from 37 months, with clearly retained features of autosomal recessive inheritance, seems to be connected with incomplete penetrance (table 2). In the subgroup 37 months to 8 years, although the $\mathrm{p}$ value for females is smaller, the reduced penetrance is difficult to prove because the subgroup is not large enough ( 25 affected subjects) (table 2). However, in the subgroup 9 to 18 years, although again small (18 affected subjects: 16 males, two females), the reduced penetrance is remarkable, probably owing to a 'female sparing factor': $p$ value for males 0.2 and for the overall subgroup below $0 \cdot 1$. The most convincing, because of the larger numbers (51 affected subjects), is the combined subgroup 37 months to 18 years with a p value for males close to the expected 0.25 , for females close to $0 \cdot 1$, and for both sexes combined $0 \cdot 17$. This might indicate about $30 \%$ reduction in penetrance in this subgroup.

As Furukawa et $a^{6}$ have suggested, sex influence may be associated with hormonal differences between males and females, the female gonadal hormones possibly playing the role of a 'female sparing factor'. Depending on the age at onset, this would be expressed:

(1) in earlier age, in a milder course of the disease in females, and in some dropping of the proportion of affected females between the third and eighth year of life;

(2) after the eighth year of life, in a significant decrease of the number of female cases; and 
(3) after the age of 13 years in an almost complete lack of female cases.

These facts might well be connected with some known milestones of female hormonal development, for instance the increase of FSH and oestrogen secretion around the eighth year of life as well as a sharp increase in some fractions of oestrogen just before the menarche, that is, around the thirteenth year of life. ${ }^{23}$

The question of whether or not the established sex influence is related to the specific form of chronic proximal SMA of childhood and adolescence remains to be answered. From the study of Namba et al, ${ }^{\mathbf{1 6}}$ it seems that the more frequent occurrence of SMA in males than in females is also, and even to a greater degree, observed in adults. However, their data should be treated with caution since they were based on material composed of all genetic forms of SMA, including the sex linked form which is clearly different. According to other sources, no sex influence was detectable in the dominant ${ }^{24}$ and in the autosomal recessive proximal adult form of the disease. ${ }^{25}$ On the other hand there was a preponderance of males in the distal autosomal recessive form of SMA. ${ }^{26}$

It is unlikely that the confirmation and explanation of the putative role played by hormones in the modulation of phenotypic expression in CPSMA could be achieved other than through experimental studies. Perhaps some known animal models of SMA $^{27} 28$ could be of help.

The authors are grateful to Professor I Wald, Head of the Genetical Department, Psychoneurological Institute, for his helpful criticism. The collection of pedigrees and testing of affected subjects was supported by a grant from the Polish Academy of Sciences, No 10.4.05.4.1.

\section{References}

1 Kugelberg E, Welander L. Familial neurogenic (spinal ?) muscular atrophy simulating ordinary proximal dystrophy. Acta Psychiatr Scand 1954;29:42-53.

2 Kugelberg E, Welander L. Heredofamilial proximal spinal (pseudomyopathic) muscular atrophy simulating muscular dystrophy. Arch Neurol 1956;75:500-9.

3 Cotton JE. L'amyotrophie neurogene pseudomyopatique. Lyon Med 1965;213:1295-8.

4 Smith JB, Patel A. The Wohlfart-Kugelberg-Welander disease. Review of the literature and report of a case. Neurology $1965 ; 15: 469-75$.

5 Cazzato G. Amiotrofia spinali progressiva pseudomiopatiche dell' adulto. Acta Neurol (Napoli) 1969;24:341-70.

- Furukawa TK, Nakao H, Sugita M, Tsukagoshi H. Kugelberg-Welander disease with particular reference to sex influenced manifestations. Arch Neurol 1968;19: 156-62.

7 Brandt S. Werdnig-Hoffmann's infantile progressive muscular dystrophy. Copenhagen: Ejnar Munskgaard, 1950.

8 Gamstorp I. Progressive spinal muscular atrophy with

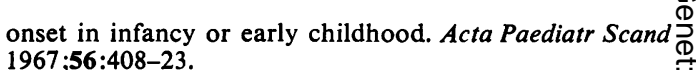

9 Winsor EJ, Murphy EG, Thompson MW, Reed TE. Genetics of childhood spinal muscular atrophy. J Med $\vec{\oplus}$ Genet $1971 ; 8: 143-8$.

10 Pearn JH, Carter CO, Wilson J. The genetic identity of acute infantile spinal muscular atrophy. Brain $1973 ; 96: \frac{O}{\bar{D}}$
$463-70$.

11 Benady SG. Spinal muscular atrophy in childhood: $\overrightarrow{\mathbb{Q}}$ review of 50 cases. Dev Med Child Neurol 1978;20:746-57.

12 Pearn JH, Bundey S, Carter CO, Wilson J, GardnerMedwin D, Walton JN. A genetic study of subacute and $\vec{D}$ chronic spinal muscular atrophy in childhood. $J$ Neurol ? Sci $1978 ; 37: 227-48$.

13 Pearn JH, Gardner-Medwin D, Wilson J. A clinical study $\vec{\omega}$ of chronic childhood spinal muscular atrophy. $J$ Neurol Sci 1978;38:23-37.

14 Schmid PC. Beitrag zum Krankenheitsbild der infantilen progressiven spinalen Muskulatrophie nach WerdnigHoffmann. $Z$ Kinderheilkd $1958 ; 81: 13-25$.

15 Dubowitz V. Infantile muscular atrophy. A prospective is

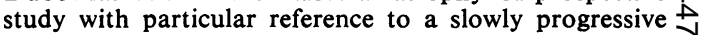
variety. Brain 1964;87:707-18.

16 Namba T, Aberfeld DC, Grob D. Chronic proximal $\frac{\circ}{\partial}$ muscular atrophy. $J$ Neurol Sci 1970;11:401-28.

17 Hausmanowa-Petrusewicz I, Zaremba J, Borkowska J. Chronic forms of childhood spinal muscular atrophy. Ф Are the problems of its genetics really solved? $J$ Neurol $\underset{\complement}{\square}$ Sci $1979 ; 43: 313-27$.

18 Hausmanowa-Petrusewicz I, Zaremba J, Borkowska J, Ф Prot J. Genetic investigations on chronic forms of infantile and juvenile spinal muscular atrophy. $J$ Neurel $\overrightarrow{0}$ 1976;213:335-46.

19 Hausmanowa-Petrusewicz I, Borkowska J, Zaremba Juvenile motor neuron disease-the sex influence benignjuvenile pseudodystrophic spinal muscular atrophy In: Rowland LP, ed. Human motor neuron disease. New York: Raven Press, 1982:131-7.

20 Zaremba J. Genetics of the chronic, proximal form of the spinal muscular atrophy. (Unpublished data.)

21 Hausmanowa-Petrusewicz I, Askanas W, Badurska B, et al. Infantile and juvenile spinal muscular atrophy. $J$ Neurol Sci 1968;6:263-87.

22 Bundey S, Lovelace RE. A clinical and genetic study of chronic proximal spinal muscular atrophy. Brain 1975; 98:455-71.

23 Widholm O, Kanfera RL, Axelson E, Johansson EDB, $\overline{\overline{3}}$ Wide L. Endocrine changes before and after the menarche. I. Urinary excretion of estrogen, FSH and LH and $\overline{0}$ serum levels of progesterone FSH and LH. Acta Obstet 3 Gynaecol Scand 1974;53:197-208.

24 Pearn JH. Autosomal dominant spinal muscular atrophy. 을 J Neurol Sci 1978;38:263-75.

25 Pearn JH, Hudgson P, Walton JN. A clinical and genetic $ᄋ$ study of adult-onset spinal muscular atrophy. The autosomal recessive form as a discrete disease entity. $\frac{7}{0}$ Brain 1978;101:591-606.

26 Harding AE, Thomas PK. Hereditary distal spinal $N$ muscular atrophy. $J$ Neurol Sci 1980;45:337-45.

27 Duchen LW, Strich JS. An hereditary motor neurone N disease with progressive denervation of muscle in the mouse. J Neurol Neurosurg Psychiatry 1968;31:535-41. W

28 Cork LC. Discussion. In: Rowland LP, ed. Human motor neuron disease. New York: Raven Press, 1982: 135-6.

Correspondence and requests for reprints to Professor Irena Hausmanowa-Petrusewicz, Neuro- logical Department, Medical School, ul Oczki 6, Warsaw, Poland. 